\title{
Interleukin-10 is a Central Regulator of the Response to LPS in Murine Models of Endotoxic Shock and the Shwartzman Reaction but not Endotoxin Tolerance
}

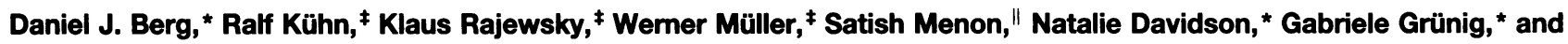 \\ Donna Rennick* \\ * Department of Immunology and "Molecular Biology, DNAX Research Institute of Cellular and Molecular Biology, Palo Alto, \\ California 94304; and ${ }^{\ddagger}$ Institute for Genetics, University of Cologne, Cologne, Federal Republic of Germany
}

\begin{abstract}
Previous studies in vivo have shown that $\mathbf{I L - 1 0}$ infusion can prevent lethal endotoxic shock. Mice deficient in the production of IL-10 (IL10T) were used to investigate the regulatory role of $\mathrm{IL-10}$ in the responses to $\mathrm{LPS}$ in three experimental systems. In a model of acute endotoxic shock, it was found that the lethal dose of LPS for IL10T mice was 20-fold lower than that for wild type (wt) mice suggesting that endogenous IL-10 determines the amount of LPS which can be tolerated without death. The high mortality rate of IL10T mice challenged with modest doses of LPS was correlated to the uncontrolled production of TNF as treatment with anti-TNF antibody (Ab) resulted in $70 \%$ survival. Additional studies suggested that IL-10 mediates protection by controlling the early effectors of endotoxic shock (e.g., TNF $\alpha$ ) and that it is incapable of directly antagonizing the production and/or actions of late appearing effector molecules (e.g., nitric oxide). We also found that IL10T mice were extremely vulnerable to a generalized Shwartzman reaction where prior exposure to a small amount of LPS primes the host for a lethal response to a subsequent sublethal dose. The priming LPS dose for IL10T mice was 100fold lower than that required to prime wt mice implying that IL-10 is important for suppressing sensitization. In agreement with this assumption, $I L-10$ infusion was found to block the sensitization step. Interestingly, IL-10 was not the main effector of endotoxin tolerance as IL10T mice could be tolerized to LPS. Furthermore, IL-10 infusion could not substitute for the desensitizing dose of LPS. These results show that IL-10 is a critical component of the host's natural defense against the development of pathologic responses to LPS although it is not responsible for LPS-induced tolerance. (J. Clin. Invest. 1995. 96:2339-2347.) Key words: IL10 - endotoxic shock - Shwartzman reaction - endotoxin tolerance
\end{abstract}

\section{Introduction}

Severe gram-negative bacterial infections can lead to the development of endotoxic shock, a state characterized by hypoten-

Address correspondence to Donna Rennick, PhD., DNAX Research Institute, 901 California Ave., Palo Alto, CA, 94304. Phone: 415-4961154; FAX: 415-496-1200

Received for publication 24 April 1995 and accepted in revised form 13 July 1995.

J. Clin. Invest.

(C) The American Society for Clinical Investigation, Inc.

0021-9738/95/11/2339/09 \$2.00

Volume 96, November 1995, 2339-2347 sion, multiorgan failure, and potentially death. This syndrome is secondary to the effects of endotoxin, the LPS-containing portion of the bacterial cell wall. Infusion of LPS mimics the endotoxic shock state (1) and results in the production of multiple inflammatory cytokines, including TNF $\alpha(2,3)$, IL-1 (4, 5 ), and IFN $\gamma(6)$. The toxicity of LPS appears to be mediated by these cytokines as passive immunization against these mediators resulted in decreased mortality $(2,6-10)$.

There has been considerable interest in the fact that LPS induces not only the production of pro-inflammatory but also the production of anti-inflammatory molecules such as IL-10 (11). IL-10 has been shown to be a potent macrophage deactivator, blocking the induced synthesis of TNF $\alpha, \mathrm{IL}-1, \mathrm{IL}-6, \mathrm{IL}-8$, and GM-CSF by human monocytes (12) and mouse peritoneal macrophages (13). IL-10 also indirectly suppresses the synthesis of IFN $\gamma$ by helper T cells (14) and NK cells (15). Based on the results of these in vitro studies, it was proposed that IL10 may be useful in the treatment of endotoxic shock. Subsequently, it was shown that a single injection of IL-10 prevented death in murine models of LPS-induced toxic shock $(16,17)$. Maximum protection was afforded only when IL-10 was given shortly before or within $30 \mathrm{~min}$ after LPS challenge. Although these studies left little doubt that IL-10 could function as a potent anti-inflammatory agent, it seemed unlikely that it could be used to treat patients already presenting with symptoms of toxic shock. It was also questionable whether endogenously produced IL-10 was normally involved in suppressing endotoxin-induced toxicity since in vitro studies had shown that the synthesis of IL-10 by LPS-stimulated macrophages occurred late $(18-24 \mathrm{~h})$ relative to that of pro-inflammatory cytokines $(2-6 \mathrm{~h})(12)$. Recently it was found that IL-10 is produced in mice very rapidly after exposure to $\operatorname{LPS}(18,19)$. In fact, serum IL-10 levels peaked at the same time as TNF $\alpha$, which is known to play a central role in the pathogenesis of endotoxic shock (3). Furthermore, administering neutralizing anti-IL-10 Ab to mice before challenge with a sublethal dose of LPS resulted in greatly increased serum IFN $\gamma$ and TNF levels and in a $60 \%$ mortality rate (19). These studies first suggested a regulatory role for endogenous IL-10 in endotoxic shock.

The generation of mice with a targeted disruption of the IL10 gene (IL10T) $)^{1}(20)$ has allowed further definition of the actions of IL-10 in complex physiologic systems. We have compared the LPS responses of IL10T and wt mice to determine the importance of endogenous IL-10 in regulating immune/ pathologic responses in an endotoxic shock model (17), the generalized Shwartzman reaction (a model of disseminated in-

1. Abbreviations used in this paper: Ab, antibody; f.p., footpad; i.p., intraperitoneal; i.v., intravenous; IL10T, mice with a targeted disruption of the IL-10 gene; wt, wild type. 
travascular coagulation and shock $)(21,22)$, and acquired endotoxin tolerance $(23,24)$.

\section{Methods}

Animals. IL10T mice generated on a C57B1/6/129-Ola background (20) and wt litter-mate controls were derived by cesarean section at Simonsen Laboratory (Gilroy, CA) and maintained in our animal facility at DNAX (Palo Alto, CA). Healthy 4-5 wk old IL10T mice were used for this study.

Reagents. LPS from Escherichia coli (serotype 0111:B4) was obtained from DIFCO (Detroit, MI) and resuspended in pyrogen-free saline. Recombinant murine IL-10 was expressed in $E$. coli as inclusion bodies and purified after renaturation to homogeneity and high sp act $\left(\sim 1.0 \times 10^{7} \mathrm{U} / \mathrm{mg}\right)$ using hydrophobic and ion exchange chromatography. The protein concentration in the purified preparations was determined by the extinction coefficient of the protein $(1 \mathrm{mg} / \mathrm{ml}=0.36$ A280). This material contained $<0.10 \mathrm{EU} / \mathrm{mg}$ protein, and remained stable at $4^{\circ} \mathrm{C}$ for at least 6 mo. The specific activity of murine IL-10 was evaluated in a proliferation assay using $\mathrm{Ba} / \mathrm{F} 3$ cells carrying the IL-10 receptor (25). Recombinant IL-10 was diluted in saline and a dose of $10 \mu \mathrm{g} /$ mouse, i.p., was administered in a total volume of $250 \mu \mathrm{l}$.

Determination of serum cytokine and NO levels. Blood samples were obtained by cardiac puncture from mice euthanized with $\mathrm{CO}_{2}$. Serum concentrations of TNF $\alpha$ and IL- $1 \alpha$ were measured using ELISA kits purchased from Genzyme (Boston, MA) as per the manufacturer's directions. Other serum cytokine levels were detected by two-site sandwich ELISA assays as previously described (26), using the following antibody pairs which were kindly provided by Dr. J. Abrams (DNAX): for IFN $\gamma, \mathrm{R} 46 \mathrm{~A} 2$, and AN18; for IL-6, 32C11, and 20F3; and for IL10 , SXC-11, and XT3. The antibodies to the p40 subunit of IL-12, C15.1.2 and C15.6.7 (27) were kindly provided by Anne O'Garra (DNAX). Biological activity of the IL-12 heterodimer was quantified by an $\mathrm{Ab}$ capture bioassay as previously described (28). Murine rIL12 purified from the supernatant of $\operatorname{COS} 7$ cells transfected with the cDNAs encoding the $\mathrm{p} 35$ and $\mathrm{p} 40$ subunits of IL-12 was kindly provided by Dr. M. Bond, DNAX. Serum nitrate levels were measured by reducing nitrate enzymatically with nitrate reductase (29). Serum was diluted 1:5 in water and the enzyme reaction was performed using a kit purchased from Boehringer-Mannheim (Indianapolis, IN) as per the manufacturer's direction.

Experimental protocol for induction of endotoxic shock. Mice were injected i.v. via the tail vein with LPS $(2.5,5,10,50,100$, or $200 \mu \mathrm{g} /$ mouse) in a saline solution of $200 \mu \mathrm{l}$ per dose and monitored for survival for $7 \mathrm{~d}$. All deaths occurred within $3 \mathrm{~d}$ of LPS administration. All protocols were reviewed and approved by the institute's (DNAX) animal care committee.

Treatment with anti-cytokine antibodies. Wt and IL10T Mice were injected intraperitoneally with various concentrations of purified rat anti-mouse neutralizing anti-cytokine Abs or isotype control Abs (2, 5 , or $10 \mathrm{mg}$ ). These Abs were administered either $4 \mathrm{~h}$ before, concurrent with or 2,4 , or $6 \mathrm{~h}$ after LPS administration as indicated in the result's section. Antibodies used herein were: anti-IL-10 (JESS-2A5); anti-IL6 (20F3); anti-TNF (XT22); anti-IFN $\gamma$ (XMG1.2); and anti- $\beta$-galactosidase (GL-117) which is referred to as the isotype control. The antiTNF antibody, XT22, was elicited against TNF $\alpha$ but neutralizes both $\mathrm{TNF} \alpha$ and TNF $\beta$. The antibody concentrations used herein have been shown to block the adverse affects of LPS in wt mice (when possible). The highest concentrations used ( $10 \mathrm{mg} / \mathrm{mouse}$ ) were 2 - to 5 -fold higher than those required to ablate the adverse affects of endogenously produced cytokines in normal mice in a model of LPS-induced toxic shock (19) or in other in vivo models $(30,31,32)$.

Experimental protocol for the generalized Shwartzman reaction and endotoxin tolerance. The generalized Shwartzman reaction and endotoxin tolerance were elicited in mice by two consecutive injections of E. coli LPS. A preparatory injection was given in varying doses in the

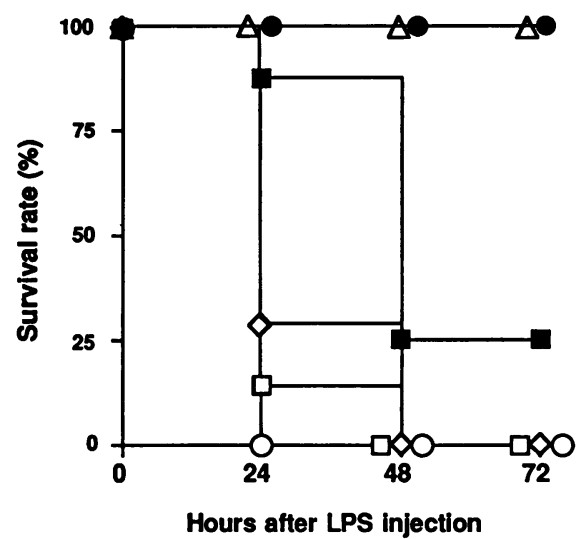

\begin{tabular}{|c|c|c|}
\hline \multirow{2}{*}{$\begin{array}{l}\text { Wrmice } \\
200 \mu \mathrm{g} \text { LPS }\end{array}$} & \multicolumn{2}{|c|}{ ll10Tmice } \\
\hline & $\Delta 2.5 \mu g$ LPS & $\diamond 50 \mu g$ LPS \\
\hline$\leq 100 \mu \mathrm{g}$ & D $5.0 \mu g$ LPS & O $100 \mu \mathrm{g} \mathrm{LF}$ \\
\hline
\end{tabular}

Figure 1. IL10T mice have increased susceptibility to endotoxic shock. IL10T and wt mice were injected with the indicated doses of LPS i.v. and monitored for survival for $7 \mathrm{~d}$. Each treatment group consisted of 6-8 wt or IL10T mice. Results are expressed as percentage of survival and are representative of three independent experiments.

f.p. followed $24 \mathrm{~h}$ later by an i.v. provoking dose (elicitation). The preparatory dose for the Shwartzman reaction in IL10T mice was 0.005 to $0.01 \mu \mathrm{g} \mathrm{LPS}$; in wt mice the dose was $1 \mu \mathrm{g}$. The provoking dose for the IL10T mice was $2.5 \mu \mathrm{g}$; for wt mice the dose was $100 \mu \mathrm{g}$. The preparatory dose for endotoxin tolerance in IL10T mice was $1.0 \mu \mathrm{g}$; in wt mice the dose was $25 \mu \mathrm{g}$. The provoking dose for the IL10T mice was 5-10 $\mu \mathrm{g}$; for wt mice the dose was $200 \mu \mathrm{g}$. In some experiments, serum was obtained at varying intervals after LPS injection (provoking dose) for measurement of cytokine levels, in the manner described above.

Statistical analysis. Significant differences between experimental groups were evaluated by the nonparametric Mann and Whitney U test.

\section{Results}

IL10T mice show increased mortality rates and dysregulated cytokine production in a model of endotoxic shock. We compared the responses of IL10T and wt mice after challenge with varying doses of LPS. IL10T mice were extremely sensitive to LPS as none survived a dose as low as $5 \mu \mathrm{g} /$ mouse (Fig. 1). In contrast, wt mice survived a dose of $100 \mu \mathrm{g} /$ mouse. These results suggested that endogenous IL-10 is important for establishing the lethal threshold dose of LPS in wt mice at a 20 -fold higher level than that observed in IL10T mice.

Cytokine levels in the sera of IL10T and wt mice were measured at various intervals after LPS administration. The dose of LPS used for this experiment was $50 \mu \mathrm{g} /$ mouse as it produced $100 \%$ mortality in IL10T mice and no mortality in wt mice (refer to Fig. 1). It was found that TNF $\alpha$ levels were greatly increased in IL10T mice as compared with wt mice (Fig. $2 \mathrm{~A}$ ). At $1 \mathrm{~h}$ post LPS challenge, the TNF $\alpha$ levels were identical in the IL10T and wt mice. In the wt mice, serum TNF $\alpha$ declined to almost undetectable levels 3-6 h after LPS. However, TNF $\alpha$ continued to increase in the sera of IL10T mice and reached a peak concentration at $3 \mathrm{~h}$ that was 30 -fold higher than the amount detected in wt mice at $3 \mathrm{~h}$. These high levels of TNF $\alpha$ were maintained in the sera of IL10T mice at 

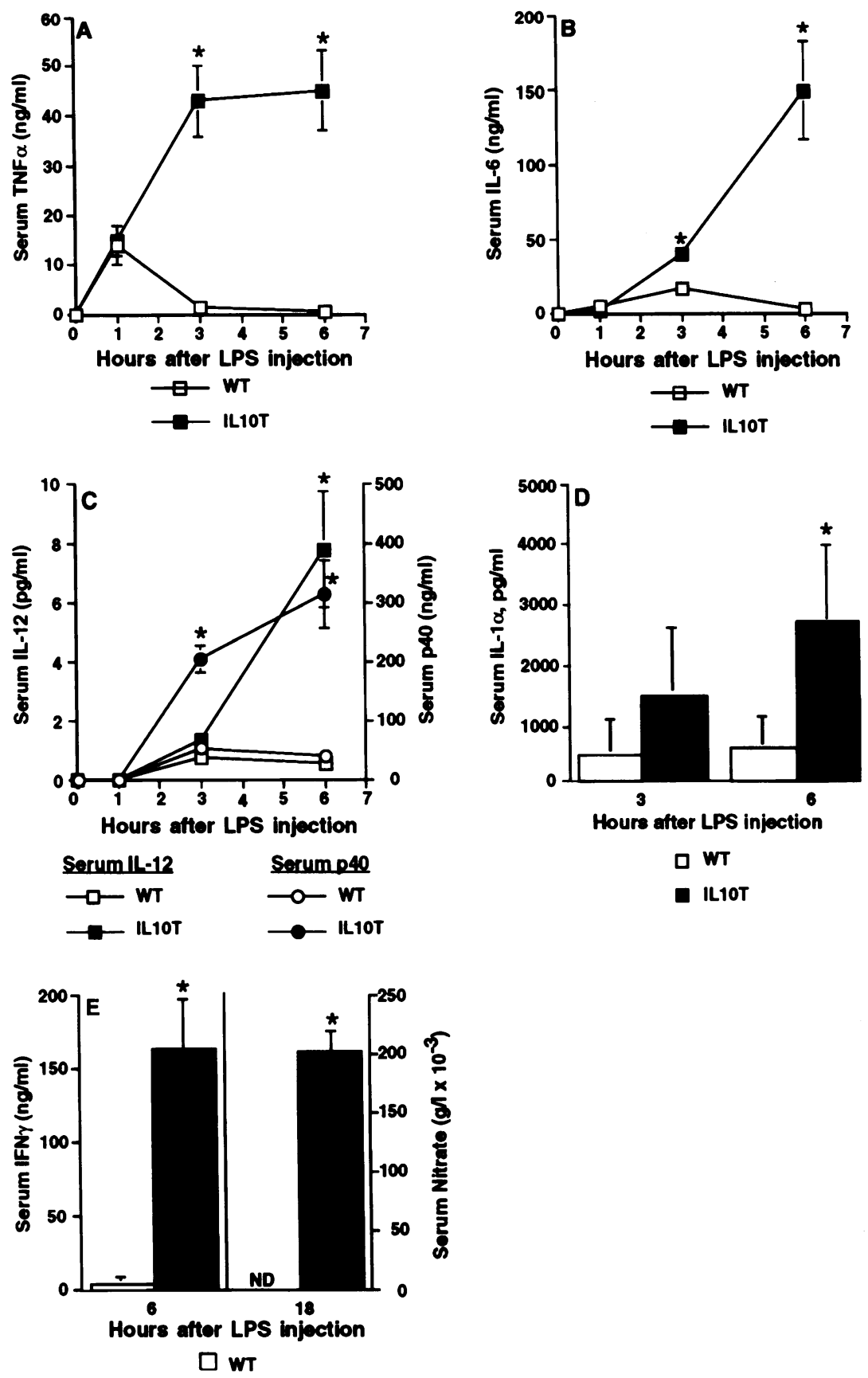

Figure 2. IL10T mice have dysregulated cytokine production after stimulation with endotoxin. LPS ( $50 \mu \mathrm{g} /$ mouse) was administered i.v. and sera collected at the indicated time points. Each data point represents the mean \pm S.D. of $6-8$ individual mice per group. $(A) \mathrm{TNF} \alpha,(B) \mathrm{IL}-6,(C)$ IL-12 bioactivity and $\mathrm{p} 40$ protein concentration, $(D) \mathrm{IL}-1 \alpha$, and (E) IFN $\gamma($ left $)$ and serum nitrate (right). Results are representative of two independent experiments. * Mann-Whitney U test, $P<0.05$, demonstrating statistical difference in serum levels between IL10T and wt mice groups. $N D$, not detected.

$6 \mathrm{~h}$ after LPS. Thus, both the kinetics and level of TNF $\alpha$ production were markedly altered in the absence of endogenous IL-10.

Similar results were observed when the levels of IL- 6 and IL-12 were measured (Fig. $2 B$ and $C$ ). As expected, the appearance of IL-6 and IL-12 in the sera of IL10T and wt mice occurred later than that of TNF $\alpha$. While the levels of these two cytokines declined in wt mice after $3 \mathrm{~h}$, they continued to rise in IL10T mice. At $6 \mathrm{~h}$ post LPS, IL-6, and IL-12 were abnormally increased in IL10T mice by 70- and 6-fold, respectively. Additionally, p40 (the inducible subunit of IL-12), IL- $\alpha$ (Fig. 2 $D$ ) and IFN $\gamma$ (Fig. $2 E$ ) were much higher in the sera of IL10T mice.

Serum nitrate could not be detected in the sera of IL10T or wt mice before or within $6 \mathrm{~h}$ of LPS administration (data not shown). However, very high levels were detected in the sera of IL10T mice at $12 \mathrm{~h}$ (data not shown) and $18 \mathrm{~h}$ post LPS administration (Fig. $2 \mathrm{E}$ ). In contrast, nitrate remained undetectable in the sera of wt mice at all time points tested (Fig. $2 E$ ).

TNF and INF $\gamma$ are mediators of mortality in ILIOT mice challenged with LPS. IL10T mice were infused with neutralizing anti-cytokine $\mathrm{Ab}$ in order to determine which cytokine(s) was contributing to their high mortality rate after challenge with $50 \mu \mathrm{g}$ of LPS, a dose which was sublethal for wt mice. In these experiments, $2 \mathrm{mg}$ of anti-TNF Ab administered $4 \mathrm{~h}$ before LPS challenge resulted in $70 \%$ survival whereas administration of 2 $\mathrm{mg}$ of the isotype control $\mathrm{Ab}$ provided no protection (Fig. 3).

Under the same experimental conditions, partial protection of IL10T mice ( $36 \%$ survival) was observed by administering 


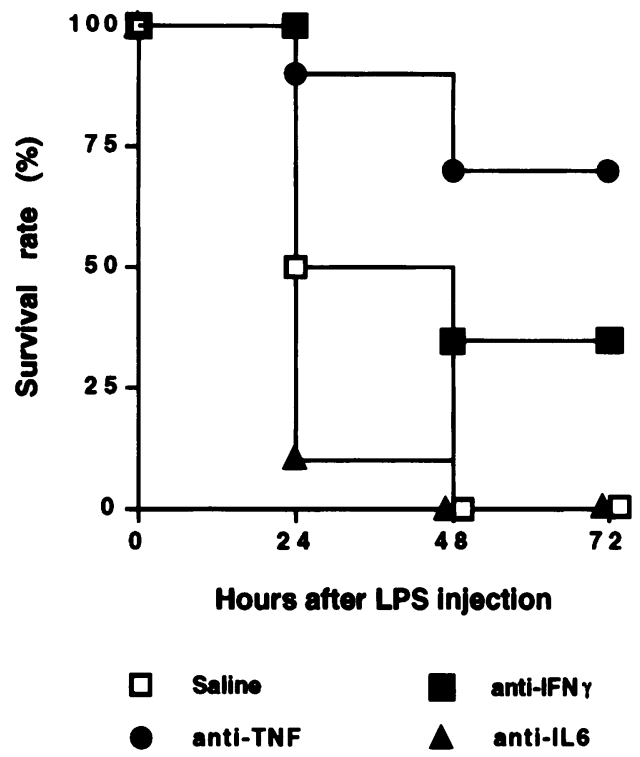

Figure 3. Anti-TNF and anti-IFN $\gamma$ Ab protects IL10T mice from lethal endotoxic shock. IL10T mice received i.p. injections of anti-cytokine antibody (anti-TNF, $2 \mathrm{mg}$; anti-IFN- $\gamma, 10 \mathrm{mg}$; anti-IL-6, $10 \mathrm{mg}$ ) or isotype control antibody (GL-117, 2 or $10 \mathrm{mg}$ ) $4 \mathrm{~h}$ before challenge with a lethal dose of LPS ( $50 \mu \mathrm{g} /$ mouse, i.v.). Each treatment group consisted of 8-10 mice. Surviving animals were monitored for $7 \mathrm{~d}$. Results are expressed as percentage of survival.

at least $10 \mathrm{mg}$ of anti-IFN $\gamma \mathrm{Ab}$. Lower amounts of anti-INF $\gamma$ (i.e., $2 \mathrm{mg}$ ) extended the survival of these mice but did not ultimately prevent their death. The diminished mortality observed in LPS-challenged IL10T mice treated with the high dose of anti-IFN $\gamma \mathrm{Ab}$ demonstrates that this cytokine contributes to their mortality. In contrast, the administration of anti-IL-6 Ab $(2-10 \mathrm{mg}$ ) failed to protect IL10T mice from the lethal effects of LPS (Fig. 3). Similar results were observed in wt mice challenged with LPS (data not shown).

Endogenously produced $I L-10$ regulates early events in endotoxic shock. Kinetic studies of IL-10 production were performed in order to further analyze the role of this cytokine in the regulation of the host's response to endotoxin. After challenge of wt mice with LPS ( $200 \mu \mathrm{g})$, it was found that serum IL-10 levels peaked within $2 \mathrm{~h}$ of challenge (Fig. $4 A$ ) and remained detectable at $6 \mathrm{~h}$. IL10T mice challenged with LPS did not produce detectable amounts of IL-10 in agreement with previous studies (20). The ability of endogenous IL-10 to protect the host against the development of lethal endotoxic shock was evaluated by administering anti-IL-10 Ab to wt mice at different time points with respect to a sublethal LPS challenge (50 $\mu \mathrm{g} /$ mouse). Neutralizing Ab to IL-10 administered $4 \mathrm{~h}$ before LPS injection reduced the survival of the wt mice to $10 \%$ as compared with $100 \%$ survival in the isotype controltreated group (Fig. $4 \mathrm{~B}$ ). If the administration of the anti-IL$10 \mathrm{Ab}$ were delayed until 3 or $6 \mathrm{~h}$ after LPS, 90 and $100 \%$ survival, respectively, were observed. These results indicate that the events regulated by endogenous IL-10 occur early in endotoxic shock.

As IL10T mice are deficient in the production of IL-10, they were infused with exogenous IL-10 $(10 \mu \mathrm{g})$ at various times relative to a lethal dose of LPS in order to further define IL-10's regulatory effects. If IL-10 infusion were given at the
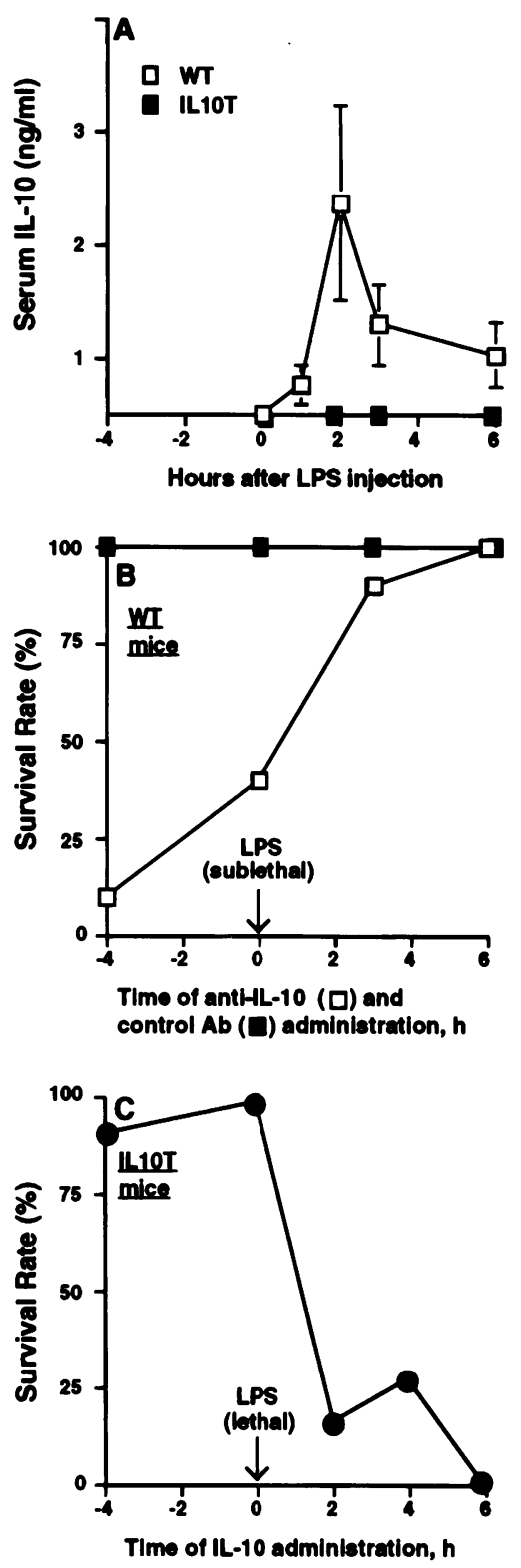

Figure 4. Endogenously produced IL-10 regulates early events in endotoxic shock. $(A)$ Measurement of serum IL-10 levels in wt and IL10T mice injected i.v. with $200 \mu \mathrm{g}$ or $50 \mu \mathrm{g}$ of LPS, respectively. Sera were collected at the indicated time points for measurement of IL-10 by ELISA Data represented are the mean \pm S.D. of 6-8 mice. (B) Early administration of neutralizing antibody to IL-10 increases the sensitivity of wt mice to LPS. Anti-IL-10 (JESS $2 \mathrm{~A} 5,2 \mathrm{mg}$ ) was administered i.p. to wt mice at the indicated time points before, concurrent, or after administration of a sublethal dose of LPS (50 $\mu \mathrm{g}$, i.v., arrow). Control groups of wt mice received an isotypematched Ab (GL-117, 2 $\mathrm{mg}$ ). Each treatment group consisted of 10 mice. Surviving animals were monitored for $7 \mathrm{~d}$. Results are expressed as percentage of survival.

(C) IL-10 administration protects IL10T mice from lethal endotoxemia IL10T mice received 50 $\mu \mathrm{g}$ of LPS i.v. at $0 \mathrm{~h}$ (arrow) and $10 \mu \mathrm{g}$ of IL10 i.p. at $-4,0,2,4$, or $6 \mathrm{~h}$ after LPS injection. Survival was monitored over the following $7 \mathrm{~d}$.

None of the saline-treated control IL10T mice survived (data not shown). Each treatment group consisted of 6 to 8 IL10T mice. Results are representative of two independent experiments and expressed as percentage of survival.

same time as LPS ( $50 \mu \mathrm{g}), 100 \%$ of the IL10T mice survived. However, if IL-10 infusion were delayed even $2 \mathrm{~h}$ after LPS challenge, no survival was observed. Identical results were obtained when a fivefold lower, but still lethal, LPS dose $(10 \mu \mathrm{g})$ was used (data not shown). These results confirmed that IL-10 must act early in order to block the pathogenic effects of LPS. Our results also show that $90 \%$ of the IL10T mice survived when IL-10 was administered $4 \mathrm{~h}$ prior to LPS challenge. This outcome suggested that IL-10 persisted in vivo long enough to directly antagonize the actions of LPS or that IL-10 invoked a state of unresponsiveness in LPS-sensitive cells. This latter possibility was addressed in the studies described below.

The regulatory effects of $I L-10$ in the generalized Shwartzman reaction. The development of the generalized Shwartzman reaction was compared in wt and IL10T mice in order to evalu- 


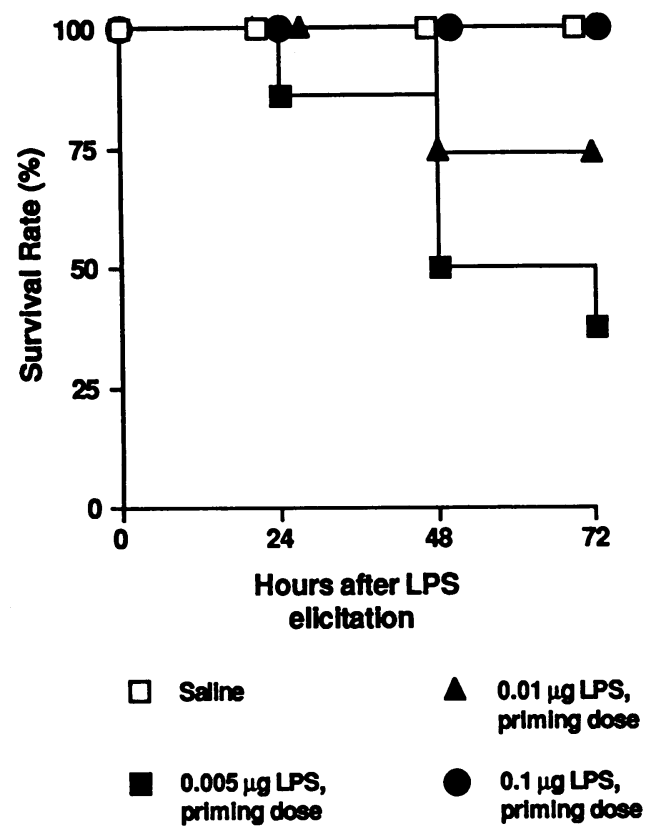

Figure 5. IL10T mice can be sensitized to LPS in the generalized Shwartzman reaction. The Shwartzman reaction was elicited in IL10T mice by two consecutive injections of LPS. The preparatory injection (0.005-0.1 $\mu \mathrm{g}$ LPS, f.p.) was followed $24 \mathrm{~h}$ later by a standard $2.5 \mu \mathrm{g}$ i.v. provoking dose. Each group consisted of 6-8 IL10T mice. Data are representative of 3 independent experiments and results are expressed as percentage of survival.

ate the role of endogenously produced IL-10 in controlling this type of LPS-induced response. Extremely small amounts of LPS (0.01-0.005 $\mu \mathrm{g}$ LPS) injected into the f.p. of IL10T mice primed them for a lethal reaction to a sublethal dose of LPS given i.v. 24 h later (Fig. 5). In contrast, a minimum dose of
$1 \mu \mathrm{g}$ LPS was required to sensitize a wt mice for a lethal reaction to a sublethal dose of LPS (data not shown). To further evaluate this phenomenon, serum cytokines were measured at various intervals after administration of the LPS elicitation dose. Prior LPS sensitization of IL10T mice lead to a transient but significant increase in TNF $\alpha$ production (Fig. $6 A$ ). In fact, the highest amount of TNF $\alpha$ induced after two consecutive nonlethal doses of LPS was similar to that induced by a single lethal dose ( see Fig. 2). In contrast, IL-6 and IFN $\gamma$ serum levels were not significantly altered by priming IL10T mice with LPS (Figs. 6, $B$ and $C$ ). In both cases, the levels observed were low as compared to those elicited by a single lethal dose of LPS (see Fig. 2).

In another set of studies, we tested the ability of exogenous IL-10 to regulate the priming phase of the generalized Shwartzman reaction. IL10T and wt mice were given either IL-10 or saline simultaneously with the priming dose of LPS (Table I). As expected, we found that IL10T and wt mice primed with LPS had high mortality rates when challenged with sublethal doses of LPS. In contrast, the mortality rates of both IL10T and wt mice were dramatically reduced if they were primed with LPS in the presence of IL-10. These results clearly demonstrate that the priming step in the Shwartzman reaction is inhibitable by IL-10.

IL10T mice develop endotoxin tolerance. Numerous studies have shown that prior exposure to low doses of LPS can result in the development of tolerance to subsequent LPS challenge. The possibility that the induction of tolerance might depend on the actions of IL-10 prompted us to test whether IL10T mice could be rendered tolerant to LPS. When IL10T mice were primed with $1 \mu \mathrm{g}$ of LPS in the f.p. and subsequently challenged with a lethal i.v. dose of LPS ( $5 \mu \mathrm{g})$, all of the mice survived (Fig. 7). IL10T mice primed with $1 \mu \mathrm{g}$ of LPS survived subsequent challenges of 5-10 $\mu$ g of LPS; however no survival was seen when the mice were challenged with $25 \mu \mathrm{g}$ of LPS (data not shown). Serum cytokines were measured at various inter-
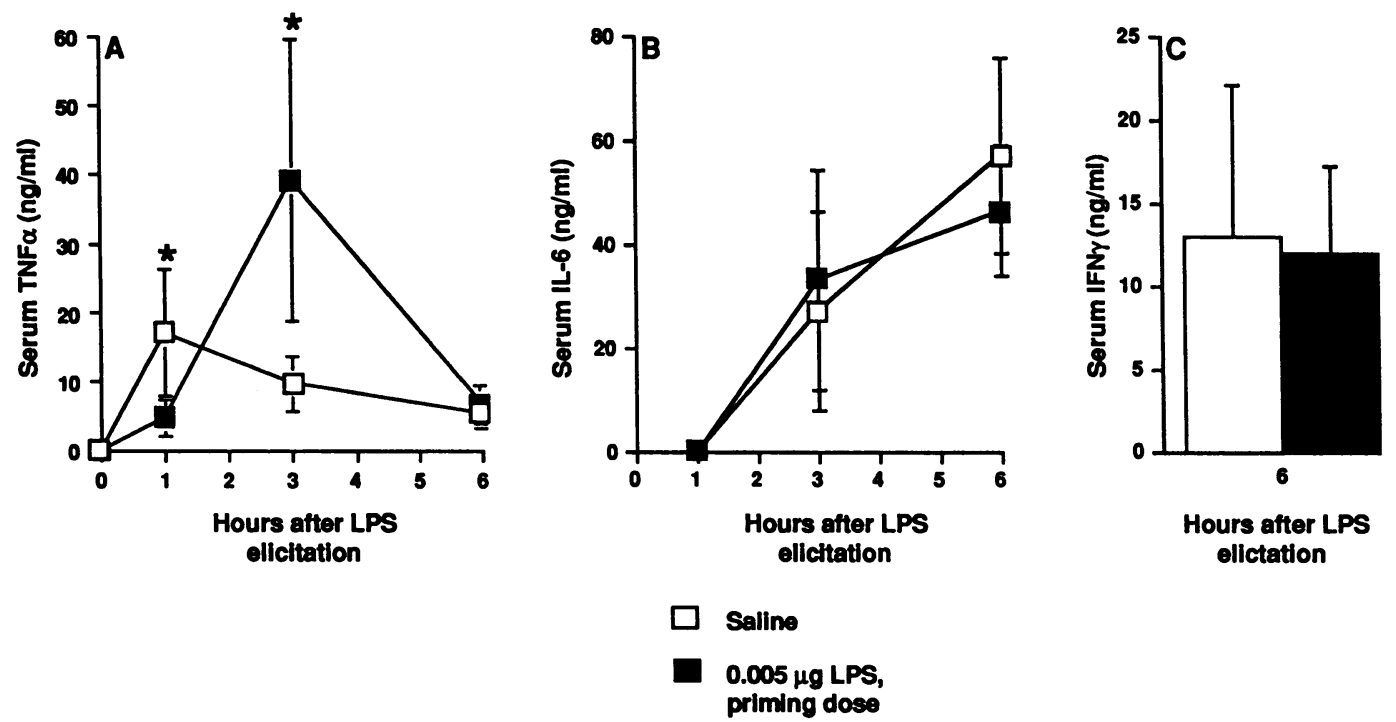

Figure 6. IL10T mice sensitized to LPS in the Shwartzman reaction have exaggerated production of TNF $\alpha$. IL10T mice received either saline or $0.005 \mu \mathrm{g} \mathrm{LPS}$ as a preparatory dose in the f.p. followed $24 \mathrm{~h}$ later by an eliciting dose of $2.5 \mu \mathrm{g}$ LPS i.v. Sera for cytokine measurement by ELISA were obtained at the indicated time points. Data represented are the mean \pm S.D. of $6-8$ individual mice per group. $(A) \mathrm{TNF} \alpha,(B) \mathrm{IL}-6$, and $(C)$ IFN $\gamma$. ${ }^{*}$ Mann-Whitney U test, $P<0.05$, demonstrating statistical difference in the levels between LPS-primed and saline-treated IL10T mice groups. 
Table I. IL-10 Inhibits the Priming Step in the Generalized Shwartzman Reaction

\begin{tabular}{lccccc}
\hline Genotype & $\begin{array}{c}\text { IL-10 } \\
\text { treatment } \\
\text { i.p., 0 }\end{array}$ & $\begin{array}{c}\text { LPS } \\
\text { priming } \\
\text { f.p., 0 }\end{array}$ & $\begin{array}{c}\text { LPS } \\
\text { elicitation } \\
\text { i.v., 24 h }\end{array}$ & $\begin{array}{c}\text { No. of } \\
\text { mice dead/ } \\
\text { tested }\end{array}$ & Mortality \\
\hline & $\mu g$ & $\mu g$ & $\mu g$ & & $\%$ \\
WT & - & - & 100 & $2 / 15$ & 13 \\
WT & 10 & - & 100 & $0 / 13$ & 0 \\
WT & - & 1 & 100 & $11 / 15$ & 73 \\
WT & 10 & 1 & 100 & $1 / 15$ & 6 \\
IL10T & - & - & 2.5 & $0 / 10$ & 0 \\
IL10T & 10 & - & 2.5 & $0 / 10$ & 0 \\
IL10T & - & 0.005 & 2.5 & $8 / 15$ & 53 \\
IL10T & 10 & 0.005 & 2.5 & $2 / 10$ & 20 \\
& & & & & \\
\hline
\end{tabular}

The generalized Shwartzman reaction was elicited by two consecutive injections of $E$. coli LPS. The preparatory injection f.p. (wt, $1 \mu \mathrm{g}$ LPS; IL10T, $0.005 \mu \mathrm{g}$ LPS) followed after $24 \mathrm{~h}$ by an i.v. eliciting dose (wt, $100 \mu \mathrm{g}$ LPS; IL10T, $2.5 \mu \mathrm{g}$ LPS). Saline or IL-10 (10 $\mu \mathrm{g})$ was administered i.p. to the indicated groups. (-) indicates the administration of saline. Data are pooled from two independent experiments.

vals after the LPS elicitation dose $(5 \mu \mathrm{g})$ and tolerance to a lethal dose of LPS was correlated with decreased TNF $\alpha$ levels (Fig. $8 A$ ). No differences in IL-6 or IFN $\gamma$ levels were detected (Fig. 8, $B$ and $C$ ).

Next we evaluated the effect of exogenous IL-10 in the development of endotoxin tolerance in wt and IL10T mice (Table II). It was found that IL-10 could not substitute for the LPS priming dose, as no tolerance to the elicitating LPS dose could be demonstrated. When IL-10 and the priming LPS dose were administered simultaneously, the induction of tolerance was not antagonized by IL-10. In fact, IL-10 administration appeared to enhance the tolerizing effects of LPS in both wt and IL10T mice.

\section{Discussion}

We have used IL10T and wt mice to further define the regulatory role of endogenous IL-10 in the immune/inflammatory

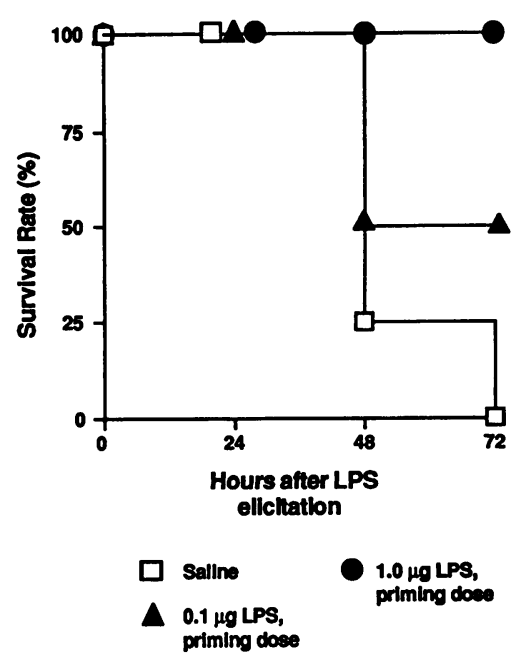

Figure 7. Endotoxin tolerance can be induced in IL10T mice. Tolerance to LPS was elicited in IL10T mice by two consecutive LPS injections, the preparatory injection $(0.1-1.0 \mu$ g, f.p.) was followed $24 \mathrm{~h}$ later by a $5 \mu \mathrm{g}$ i.v. eliciting dose. Each group consisted of 6-8 IL10T mice. Data are representative of three independent experiments and results are expressed as percentage of survival. responses elicited in vivo by LPS. In a model of acute endotoxemia, our comparative studies showed that the amount of LPS which induced lethal endotoxic shock in IL10T mice was at least 20 -fold lower than that required by wt mice. These results suggest that the host's endogenous IL-10 level determines the amount of endotoxin which constititutes a lethal threshold dose. In support of this conclusion, it was found that infusing IL10T mice with $10 \mu \mathrm{g}$ of IL-10 enabled them to survive a 10 -fold higher dose of LPS $(50 \mu \mathrm{g})$ than their untreated littermates. Presumably, the administration of small doses of recombinant IL-10 $(0.5-1.0 \mu \mathrm{g})$ used to protect normal mice from lethal doses of LPS $(16,17)$ reflects the added protection gained by boosting their endogenous IL-10 levels.

The high mortality rate observed in IL10T mice challenged with LPS was correlated with greatly elevated levels of serum TNF $\alpha$ and INF $\gamma$. The heightened production of these two cytokines in response to LPS had been observed in mice rendered IL-10-deficient by anti-IL-10 Ab (19). Herein, high levels of serum IL- $1 \alpha$, IL-6, IL-12, and nitrate were also detected in the sera of LPS-challenged IL10T mice. Wt mice which survived the same dose of LPS produced low, transient levels of serum cytokines and no detectable nitrate. Although it was shown previously that IL-10 was capable of suppressing the in vitro production of these various pro-inflammatory mediators $(12$, 13), our studies with IL10T mice and those using neutralizing $\mathrm{Ab}$ (19) have demonstrated that endogenous IL-10 is essential for controlling their in vivo production.

Even though a bolus i.v. injection of LPS induced the exaggerated production of multiple pro-inflammatory mediators in IL-10-deficient mice, significant protection was provided by prior treatment with anti-TNF Ab. These preliminary results suggested that the uncontrolled production of TNF plays an important role in the increased susceptibility of IL10T mice to endotoxic shock. It is well known that TNF $\alpha$ not only causes tissue necrosis and organ failure, but is also a potent inducer of the enzyme nitric oxide synthase which is required for the production of nitric oxide (33). Nitric oxide has been implicated in the induction of hypotension and vascular unresponsiveness (34-36) associated with endotoxic shock. Because elevated serum nitrate levels were observed in IL10T mice but were absent in normal mice stimulated with the same dose of LPS, it seems likely that the unregulated production of nitric oxide contributes to the high mortality rates observed in the IL10T mice. The exaggerated production of nitric oxide in response to such low levels of LPS may reflect the absence of IL-10's regulatory effects on TNF $\alpha$ production.

Others have used a similar model of endotoxic shock to show that the survival rates of normal mice challenged with lethal doses of LPS were improved substantially by the administration of anti-IFN $\gamma \mathrm{Ab}(6,10)$. Conversely, survival rates of normal mice challenged with a $\mathrm{LD}_{50}$ of $E$. coli were greatly diminished if the mice were pretreated with IFN $\gamma(6)$. Furthermore, high mortality rates were observed in normal mice treated with a combination of IFN $\gamma$ and TNF $\alpha$ at doses that were nonlethal when administered alone (6). These latter studies were intriguing since they suggested that IFN $\gamma$ may play a detrimental role by augmenting the pathogenic effects of TNF $\alpha$. The improved survival observed in LPS-challenged IL10T mice treated with anti-IFN $\gamma$ Ab supports the premise that IFN $\gamma$ contributes to endotoxic shock. Although we did not use anti-IL$1 \mathrm{Ab}$ or IL1 receptor antagonist (IL-1RA) in this study, it has been shown that these agents can prevent lethality in animal 

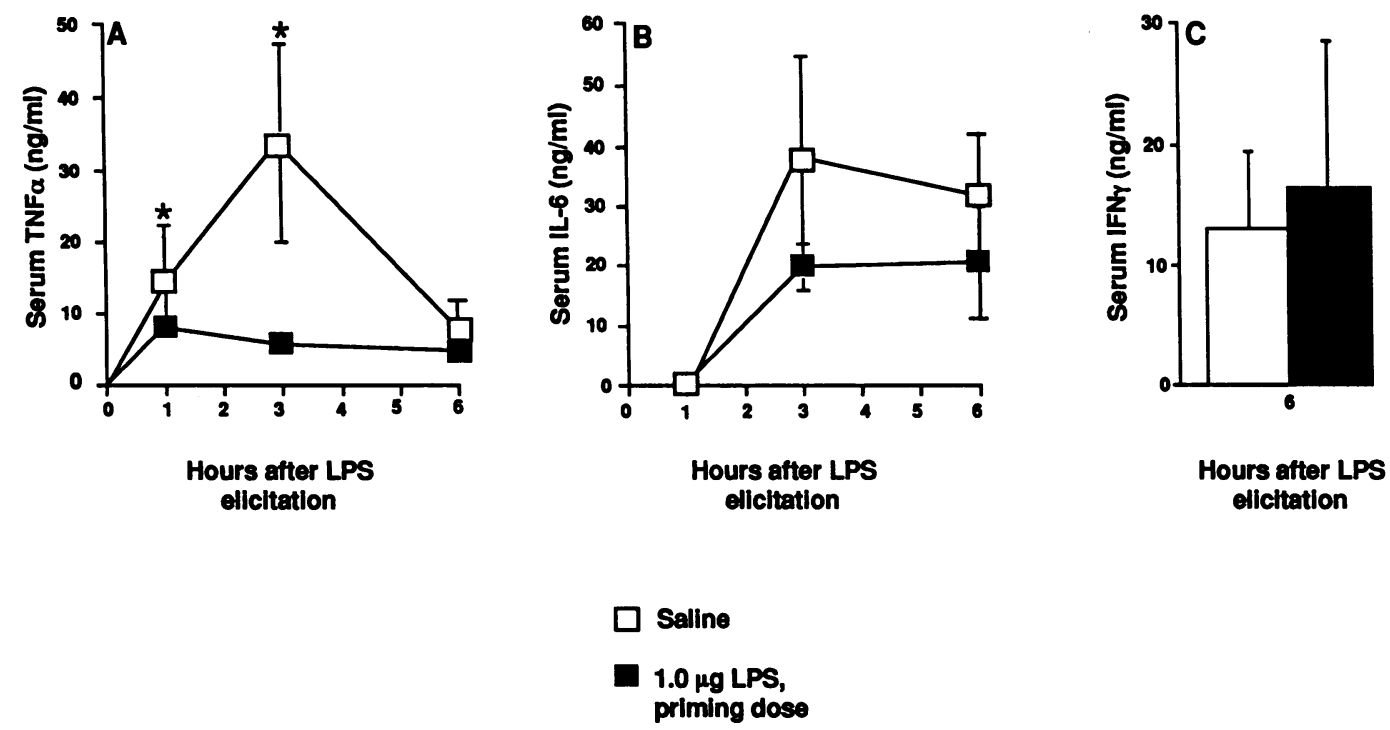

Figure 8. IL10T mice tolerized to LPS have decreased production of TNF $\alpha$. IL10T mice received either saline or $1.0 \mu \mathrm{g}$ LPS as a preparatory dose in the f.p. followed after $24 \mathrm{~h}$ by an eliciting dose of $5 \mu \mathrm{g}$ LPS, i.v. Sera for cytokine measurement by ELISA were obtained at the indicated time points. Data represented are the mean \pm S.D. of 6-8 individual mice per group. $(A)$ TNF $\alpha,(B)$ IL-6, and $(C)$ IFN $\gamma$. ${ }^{*}$ Mann-Whitney $U$ test, $P$ $<0.05$, demonstrating statistical difference in the levels between LPS-tolerized and saline-treated IL10T mice groups.

models of sepsis $(8,9,37)$. Clearly toxic shock is mediated by a complex set of cytokine interactions (2-10). Thus, the lethal threshold dose of LPS for IL10T mice may be extremely low as compared to that for wt mice because IL10T mice are incapable of regulating not only TNF $\alpha$ production but also the production of other mediators which may function as amplifiers (i.e., IFN $\gamma$ and IL-1) or as effectors of endotoxic shock.

As we and others $(18,19)$ have found that IL-10 appears in the sera of normal mice within $1 \mathrm{~h}$ after LPS challenge and persists in their blood for at least $6 \mathrm{~h}$, we investigated the possibility that IL-10 may be important for directly suppressing late as well as early events leading to endotoxic shock. Our prelimary experiments confirmed that treatment of wt mice with

Table II. IL-10 Cannot Substitute for the LPS Priming Step in Tolerance

\begin{tabular}{lccccr}
\hline Genotype & $\begin{array}{c}\text { IL-10 } \\
\text { treatment } \\
\text { i.p., 0 h }\end{array}$ & $\begin{array}{c}\text { LPS } \\
\text { priming } \\
\text { f.p., 0 h }\end{array}$ & $\begin{array}{c}\text { LPS } \\
\text { elicitation } \\
\text { i.v., 24 h }\end{array}$ & $\begin{array}{c}\text { No. of } \\
\text { mice alive/ } \\
\text { tested }\end{array}$ & Survival \\
\hline & $\mu g$ & $\mu g$ & $\mu g$ & & $\%$ \\
WT & - & - & 200 & $0 / 18$ & 0 \\
WT & 10 & - & 200 & $0 / 15$ & 0 \\
WT & - & 25 & 200 & $13 / 18$ & 72 \\
WT & 10 & 25 & 200 & $18 / 18$ & 100 \\
IL10T & - & - & 10 & $0 / 15$ & 0 \\
IL10T & 10 & - & 10 & $0 / 15$ & 0 \\
IL10T & - & 1 & 10 & $13 / 15$ & 87 \\
IL10T & 10 & 1 & 10 & $15 / 15$ & 100 \\
& & & & & \\
\hline
\end{tabular}

Tolerance to LPS was elicited by two consecutive injections of $E$. coli LPS. The preparatory f.p. injection (wt, $25 \mu \mathrm{g}$ LPS; IL10T, $1 \mu \mathrm{g}$ LPS) was followed $24 \mathrm{~h}$ later by an i.v. eliciting dose of LPS (wt, $200 \mu \mathrm{g}$ LPS; IL10T, $10 \mu \mathrm{g}$ LPS). Saline or IL-10 (10 $\mu \mathrm{g})$ was administered i.p. to the indicated groups. ( - ) indicates the administration of saline. Data are pooled from two independent experiments.
anti-IL-10 Ab prior to challenge with a sublethal dose of LPS resulted in high mortality rates (19). We also observed decreased survival in wt mice given anti-IL-10 Ab at the same time as LPS but not when the Ab-treatment was delayed until $3 \mathrm{~h}$ after challenge. Based on the results of these in vivo kinetic studies, it appeared that IL-10 mediates protection in the earliest phase of the LPS response. In our studies with IL10T mice, the importance of IL-10 in controlling early and late events was investigated by administering IL-10 at different times relative to a low $\mathrm{LD}_{100}(10 \mu \mathrm{g})$ and a high $\mathrm{LD}_{100}(50 \mu \mathrm{g})$ of LPS. We found that IL10T mice were completely protected if IL-10 were administered just prior to or at the same time as LPS. The failure of IL-10 to protect mice when administered even two hours after challenge with either a low or high $L D_{100}$ further demonstrates that IL-10 plays a critical role in regulating early events such as TNF $\alpha$ production. The pathological effects of late appearing mediators, such as IFN $\gamma$ and nitric oxide, are most likely diminished as a consequence of IL-10's suppressive actions on TNF $\alpha$ production.

We have also investigated whether IL-10 plays a regulatory role in the generalized Shwartzman reaction $(21,22)$. This reaction requires two consecutive, relatively low doses of LPS and is clinically manifested as a shock syndrome. Because the amount, route and timing of the LPS injections are critical for the phenomenon to occur, it was proposed that the Shwartzman reaction is dependent on a cascade of inflammatory mediators (38-40). Recently, it has been shown that the first dose of LPS induces the production of IL-12 (41). IL-12 subsequently stimulates the production of IFN $\gamma$ which then prepares macrophages and other cell types to release large amounts of inflammatory cytokines in response to the second, provoking dose of LPS (41). It appears that TNF $\alpha$ is the critical effector of lethality in primed mice but its actions require the presence of either IL- $1 \alpha$ or INF $\gamma(39,41)$. After recognizing that the sequential actions of very specific cytokines are involved in generating the Shwartzman reaction (41) and based on what was known about the in vitro kinetics of IL-10 production (12), it was 
predicted (41) that any putative inhibitory effects of endogenous IL-10 would occur only during the second LPS challenge. However, our comparative studies have shown that only miniscule amounts of LPS were required to prime IL10T mice for the enhanced release of TNF $\alpha$. The finding that 200 -fold more LPS was needed to prime wt mice suggests that endogenous IL-10 normally inhibits IL- 12 and IFN $\gamma$ production in response to small amounts of LPS during the prepatory phase.

In support of this conclusion, we formally demonstrated that IL-10 is capable of blocking LPS priming in the Shwartzman reaction. Hence, IL-10T and wt mice primed with LPS together with IL-10 were protected from a lethal provoking LPS dose. When cytokine levels in the serum of primed and unprimed IL10T mice were compared, no differences were observed in their IL- 6 or IFN $\gamma$ production after LPS challenge. However, elevated TNF $\alpha$ levels were found in the primed mice further indicating that alterations in TNF $\alpha$ production are a necessary prerequisite for a lethal Shwartzman reaction $(39,41)$. These results also support the conclusion that IL-10 normally suppresses the host's reactions to minimal amounts of LPS thus preventing increased susceptibility to systemic shock.

Tolerance to endotoxin can develop in animals exposed repeatedly to sublethal doses of LPS or exposed to a single low dose of LPS albeit higher than that used to prime for the Shwartzman reaction (23). Tolerance occurs rapidly (24-96 h) and has been correlated with the suppressed production of inflammatory mediators $(23,39,42)$. It has been proposed that hyporesponsiveness may result from the induction of both inflammatory and anti-inflammatory factors following exposure to LPS. The supernatants of macrophages tolerized in vitro to LPS have been shown to contain a factor capable of rendering naive macrophages refractory to LPS stimulation (43). We have tested the possibility that IL-10 is the factor responsible for LPSinduced tolerance. The results of our studies clearly suggest otherwise since certain doses of LPS could establish a state of hyporesponsiveness in IL10T mice. As a result, the survival rate upon lethal LPS challenge was $87 \%$ as compared with $0 \%$ in the untolerized group. Evaluation of cytokines in the sera of tolerized IL10T mice showed that protection correlated with suppressed TNF $\alpha$ production; no alterations were seen in either IL-6 or IFN $\gamma$ production.

A potential role for IL-10 in establishing LPS-induced tolerance was further evaluated by administering exogenous IL-10 to IL-10T and wt mice. Herein, it was shown that IL-10 infusion could not substitute for LPS in eliciting tolerance since none of the IL-10-treated animals survived a subsequent lethal LPS challenge. Nevertheless, the injection of IL-10 together with LPS during the desensitization step resulted in a slight enhancement of the survival rate $(100 \%)$ over that obtained with just LPS ( 72 and $87 \%$ ). Collectively, our results show that the mechanism of LPS-induced tolerance is not dependent on IL10 , although IL-10 may serve to potentiate the process. Several anti-inflammatory factors are produced in response to LPS and may mediate acquired tolerance to endotoxin. Examples include the IL-1RA (44) and IL-6 (45). Other possibilities include modulation of the LPS receptor or post-receptor events after LPS stimulation $(46,47)$ as well as the production of the protein BPI (bactericidal/permeability-increasing protein) from LPSactivated PMNs (48). It is interesting to note that the production of one of these anti-inflammatory agents, the IL-1RA, has already been shown to be enhanced by IL-10 (49-51).

The host's reactivity to LPS is a key part of a defensive immune/inflammatory response to gram-negative bacteria Containment and elimination of infectious organisms are accomplished in part through the production of inflammatory mediators, however, excessive production of these same mediators can result in pathology ranging from tissue damage to lethal endotoxic shock. Regulatory mechanisms have evolved to limit immune/inflammatory responses in order to avoid immunopathologic damage. Our studies demonstrate that IL-10 has a central role in regulating the host's response to endotoxin. The ability of IL-10 to suppress directly or indirectly the LPS-induced production of pro-inflammatory mediators appears critical in determining the host's susceptibility to pathogenic reactions as no compensatory mechanisms existed in the IL10T mice which substituted for the IL-10 deficiency. Our studies also suggest that IL-10 may have a therapeutic role in the modification of responses to LPS.

\section{Acknowledgments}

DNAX Research Institute of Molecular and Cellular Biology is supported by Schering-Plough Corporation.

\section{References}

1. Watson, R. W., H. P. Redmond, and H. D. Bouchier. 1994. Role of endotoxin in mononuclear phagocyte-mediated inflammatory responses. J. Leukoc. Biol. 56:95-103.

2. Beutler, B., I. W. Milsark, and A. C. Cerami. 1985. Passive immunization against cacbectin/tumor necrosis factor protects mice from lethal effect of endotoxin. Science (Wash. DC). 229:869-871.

3. Beutler, B., and A. Cerami. 1986. Cachectin/tumor necrosis factor: an endogenous mediator of shock and inflammation. Immunol. Res. 5:281-293.

4. Dinarello, C. A. 1991. The proinflammatory cytokines interleukin-1 and tumor necrosis factor and treatment of the septic shock syndrome. J. Infect. Dis. 163:1177-1184

5. Okusawa, S., J. A. Gelfand, T. Ikejima, R. J. Connolly, and C. A. Dinarello 1988. Interleukin 1 induces a shock-like state in rabbits. Synergism with tumo necrosis factor and the effect of cyclooxygenase inhibition. J. Clin. Invest. 81:1162-1172.

6. Doherty, G. M., J. R. Lange, H. N. Langstein, H. R. Alexander, C. M. Buresh, and J. A. Norton. 1992. Evidence for IFN-gamma as a mediator of the lethality of endotoxin and tumor necrosis factor-alpha. J. Immunol. 149:16661670.

7. Tracey, K. J., Y. Fong, D. G. Hesse, K. R. Manogue, A. T. Lee, G. C. Kuo, S. F. Lowry, and A. Cerami. 1987. Anti-cachectin/TNF monoclonal antibodies prevent septic shock during lethal bacteraemia. Nature (Lond.). 330:662-664.

8. Ohlsson, K., P. Bjork, M. Bergenfeldt, R. Hageman, and R. C. Thompson. 1990. Interleukin-1 receptor antagonist reduces mortality from endotoxin shock. Nature (Lond.). 348:550-552

9. Wakabayashi, G., J. A. Gelfand, J. F. Burke, R. C. Thompson, and C. A. Dinarello. 1991. A specific receptor antagonist for interleukin 1 prevents Esche richia coli- induced shock in rabbits. FASEB (Fed. Am. Soc. Exp. Biol.) J. 5:338343.

10. Kohler, J., D. Heumann, G. Garotta, R. D. Le, S. Bailat, C. Barras, J. D. Baumgartner, and M. P. Glauser. 1993. IFN-gamma involvement in the severity of gram-negative infections in mice. J. Immunol. 151:916-921.

11. Moore, K. W., A. O'Garra, W. M. R. de, P. Vieira, and T. R. Mosmann. 1993. Interleukin-10. Annu. Rev. Immunol. 11:165-190.

12. de Waal-Malefyt, R., J. Abrams, B. Bennett, C. G. Figdor, and J. de Vries. 1991. Interleukin 10 (IL-10) inhibits cytokine synthesis by human monocytes: an autoregulatory role of IL-10 produced by monocytes. J. Exp. Med. 174:12091220.

13. Fiorentino, D. F., A. Zlotnik, T. R. Mosmann, M. Howard, and A. O'Garra. 1991. IL-10 inhibits cytokine production by activated macrophages. J. Immunol. 147:3815-3822.

14. Fiorentino, D. F., M. W. Bond, and T. R. Mosmann. 1989. Two types of mouse $\mathrm{T}$ helper cell. IV. Th2 clones secrete a factor that inhibits cytokine production by Th1 clones. J. Exp. Med. 170:2081-2095.

15. Hsu, D. H., K. W. Moore, and H. Spits. 1992. Differential effects of IL4 and IL-10 on IL-2-induced IFN-gamma synthesis and lymphokine-activated killer activity. Int. Immunol. 4:563-569.

16. Gerard, C., C. Bruyns, A. Marchant, D. Abramowicz, P. Vandenabeele A. Delvaux, W. Fiers, M. Goldman, and T. Velu. 1993. Interleukin 10 reduces 
the release of tumor necrosis factor and prevents lethality in experimental endotoxemia. J. Exp. Med. 177:547-550.

17. Howard, M., T. Muchamuel, S. Andrade, and S. Menon. 1993. Interleukin 10 protects mice from lethal endotoxemia. J. Exp. Med. 177:1205-1208.

18. Durez, P., D. Abramowicz, C. Gerard, M. M. Van, Z. Amraoui, C. Dubois, O. Leo, T. Velu, and M. Goldman. 1993. In vivo induction of interleukin 10 by anti-CD3 monoclonal antibody or bacterial lipopolysaccharide: differential modulation by cyclosporin A. J. Exp. Med. 177:551-555.

19. Marchant, A., C. Bruyns, P. Vandenabeele, M. Ducarme, C. Gerard, A. Delvaux, G. D. De, D. Abramowicz, T. Velu, and M. Goldman. 1994. Interleukin10 controls interferon-gamma and tumor necrosis factor production during experimental endotoxemia. Eur. J. Immunol. 24:1167-1171.

20. Kuhn, R., J. Lohler, D. Rennick, K. Rajewsky, and W. Muller. 1993. Interleukin-10-deficient mice develop chronic enterocolitis. Cell. 75:263-274.

21. Billiau, A. 1988. Gamma-interferon: the match that lights the fire? Immunol. Today. 9:37-40.

22. Brozna, J. P. 1990. Shwartzman reaction. Semin. Thromb. Hemost. 16:326-332.

23. Mengozzi, M., and P. Ghezzi. 1993. Cytokine down-regulation in endotoxin tolerance. Eur. Cytokine. Netw. 4:89-98.

24. Johnston C. A., G., S. E. 1985. Mechanisms of endotoxin tolerance. In Pathophysiology of Endotoxin. R. Proctor Hinshaw, LB, editors. Elsevier Science Publishers, Amsterdam, the Netherlands. 359-401.

25. Ho, A. S., Y. Liu, T. A. Khan, D. H. Hsu, J. F. Bazan, and K. W. Moore. 1993. A receptor for interleukin 10 is related to interferon receptors. Proc. Natl. Acad. Sci. USA. 90:11267-11270.

26. Abrams, J. S., M. G. Roncarolo, H. Yssel, U. Andersson, G. J. Gleich, and J. E. Silver. 1992. Strategies of anti-cytokine monoclonal antibody development: immunoassay of IL-10 and IL-5 in clinical samples. Immunol. Rev. 127:5-24.

27. Gazzinelli, R. T., M. Wysocka, S. Hayashi, E. Y. Denkers, S. Hieny, P. Caspar, G. Trinchieri, and A. Sher. 1994. Parasite-induced IL-12 stimulates early IFN-gamma synthesis and resistance during acute infection with Toxoplasma gondii. J. Immunol. 153:2533-2543.

28. D'Andrea, A., A. M. Aste, N. M. Valiante, X. Ma, M. Kubin, and G. Trinchieri. 1993. Interleukin 10 (IL-10) inhibits human lymphocyte interferon gamma-production by suppressing natural killer cell stimulatory factor/IL-12 synthesis in accessory cells. J. Exp. Med. 178:1041-1048.

29. Schmidt, H. H., P. Wilke, B. Evers, and E. Bohme. 1989. Enzymatic formation of nitrogen oxides from L-arginine in bovine brain cytosol. Biochem. Biophys. Res. Commun. 165:284-291.

30. Brocke, S., A. Gaur, C. Piercy, A. Gautam, K. Gijbels, C. G. Fathman, and L. Steinman. 1993. Induction of relapsing paralysis in experimental autoimmune encephalomyelitis by bacterial superantigen. Nature (Lond.). 365:642-644.

31. Powrie, F., S. Menon, and R. L. Coffman. 1993. Interleukin-4 and interleukin-10 synergize to inhibit cell-mediated immunity in vivo. Eur. J. Immunol. 23:3043-3049.

32. Jilka, R. L., G. Hangoc, G. Girasole, G. Passeri, D. C. Williams, J. S Abrams, B. Boyce, H. Broxmeyer, and S. C. Manolagas. 1992. Increased osteoclast development after estrogen loss: mediation by interleukin-6. Science (Wash. DC). 257:88-91.

33. Cunha, F. Q., J. Assreuy, D. W. Moss, D. Rees. L. M. Leal, S. Moncada, M. Carrier, C. A. O'Donnell, and F. Y. Liew. 1994. Differential induction of nitric oxide synthase in various organs of the mouse during endotoxemia: role of TNF-alpha and IL-1 beta. Immunology. 81:211-215.

34. Kilbourn, R. G., A. Jubran, S. S. Gross, O. W. Griffith, R. Levi, J. Adams, and R.F. Lodato. 1990. Reversal of endotoxin-mediated shock by NG-methyl-L- arginine, an inhibitor of nitric oxide synthesis. Biochem. Biophys. Res. Commun. 172:1132-1138

35. Kilbourn, R. G., S. S. Gross, A. Jubran, J. Adams, O. W. Griffith, R Levi, and R. F. Lodato. 1990. NG-methyl-L-arginine inhibits tumor necrosis factor-induced hypotension: implications for the involvement of nitric oxide. Proc. Natl. Acad. Sci. USA. 87:3629-3632.

36. Nava, E., R. M. Palmer, and S. Moncada. 1992. The role of nitric oxide in endotoxic shock: effects of NG-monomethyl-L-arginine. J. Cardiovasc. Pharmacol. 20:4-6.

37. Dinarello, C. A., J. A. Gelfand, and S. M. Wolff. 1993. Anticytokine strategies in the treatment of the systemic inflammatory response syndrome. $J$. Am. Med Assoc. 269:1829-1835.

38. Heremans, H., R. Dijkmans, H. Sobis, F. Vandekerckhove, and A. Billiau 1987. Regulation by interferons of the local inflammatory response to bacterial lipopolysaccharide. J. Immunol. 138:4175-4179.

39. Heremans, H., D. J. Van, C. Dillen, R. Dijkmans, and A. Billiau. 1990 Interferon gamma, a mediator of lethal lipopolysaccharide-induced Shwartzmanlike shock reactions in mice. J. Exp. Med. 171:1853-1869.

40. Heremans, H., C. Dillen, D. J. van, and A. Billiau. 1994. Essential role for natural killer cells in the lethal lipopolysaccharide-induced Shwartzman-like reaction in mice. Eur. J. Immunol. 24:1155-1160.

41. Ozmen, L., M. Pericin, J. Hakimi, R. A. Chizzonite, M. Wysocka, G. Trinchieri, M. Gately, and G. Garotta. 1994. Interleukin 12, interferon gamma, and tumor necrosis factor alpha are the key cytokines of the generalized Shwartzman reaction. J. Exp. Med. 180:907-915.

42. Mengozzi, M., G. Fantuzzi, M. Sironi, M. Bianchi, M. Fratelli, G. Peri, S. Bernasconi, and P. Ghezzi. 1993. Early down-regulation of TNF production by LPS tolerance in human monocytes: comparison with IL-1 $\beta$, IL-6, and IL-8. Lymphokine Cytokine Res. 12:231-236.

43. Fahmi, H., and R. Chaby. 1993. Selective refractoriness of macrophage to endotoxin-induced production of tumor necrosis factor, elicited by an autocrine mechanism. J. Leukoc. Biol. 53:45-52.

44. Hannum, C. H., C. J. Wilcox, W. P. Arend, F. G. Joslin, D. J. Dripps, P. L. Heimdal, L. G. Armes, A. Sommer, S. P. Eisenberg, and R. C. Thompson. 1990. Interleukin-1 receptor antagonist activity of a human interleukin-1 inhibitor. Nature (Lond.). 343:336-340.

45. Barton, B. E., and J. V. Jackson. 1993. Protective role of interleukin 6 in the lipopolysaccharide-galactosamine septic shock model. Infect. Immun. 61:1496-1499.

46. Labeta, M. O., J. J. Durieux, G. Spagnoli, N. Fernandez, J. Wijdenes, and R. Herrmann. 1993. CD14 and tolerance to lipopolysaccharide: biochemical and functional analysis. Immunology. 80:415-423.

47. Ziegler, H. H., A. Wedel, W. Schraut, M. Strobel, P. Wendelgass, T Sternsdorf, P. A. Bauerle, J. G. Haas, and G. Riethmuller. 1994. Tolerance to lipopolysaccharide involves mobilization of nuclear factor kappa B with predominance of p50 homodimers. J. Biol. Chem. 269:17001-17004

48. Elsbach, P., and J. Weiss. 1993. Bactericidal/permeability increasing protein and host defense against gram-negative bacteria and endotoxin. Curr. Opin Immunol. 5:103-107.

49. Cassatella, M. A., L. Meda, S. Bonora, M. Ceska, and G. Constantin 1993. Interleukin 10 (IL-10) inhibits the release of proinflammatory cytokine from human polymorphonuclear leukocytes. Evidence for an autocrine role of tumor necrosis factor and IL-1 beta in mediating the production of IL-8 triggered by lipopolysaccharide. J. Exp. Med. 178:2207-2211.

50. de Waal-Malefyt, R., H. Yssel, M. G. Roncarolo, H. Spits, and J. de Vries 1992. Interleukin-10. Curr. Opin. Immunol. 4:314-320.

51. Jenkins, J. K., M. Malyak, and W. P. Arend. 1994. The effects of interleukin-10 on interleukin-1 receptor antagonist and interleukin-1 beta production in human monocytes and neutrophils. Lymphokine Cytokine Res. 13:47-54. 